\title{
The beneficial effects of honeybee-venom serum on facial wrinkles in humans
}

This article was published in the following Dove Press journal:

Clinical Interventions in Aging

I October 2015

Number of times this article has been viewed

\author{
Sang Mi Han' \\ In Phyo Hong' \\ Soon Ok Woo' \\ Sung Nam Chun ${ }^{2}$ \\ Kwan Kyu Park ${ }^{3}$ \\ Young Mee Nicholls ${ }^{4}$ \\ Sok Cheon Pak ${ }^{5}$ \\ 'Department of Agricultural Biology, \\ National Academy of Agricultural \\ Science, Wanju, ${ }^{2}$ Dong Sung \\ Pharmaceuticals Co Ltd, Seoul, \\ ${ }^{3}$ Department of Pathology, School \\ of Medicine, Catholic University \\ of Daegu, Daegu, South Korea; \\ ${ }^{4}$ Manuka Doctor Ltd, Auckland, \\ New Zealand; ${ }^{5}$ School of Biomedical \\ Sciences, Charles Sturt University, \\ Bathurst, NSW, Australia
}

Correspondence: Sang Mi Han

Department of Agricultural Biology, National Academy of Agricultural

Science, Wanju, Jeollabuk-do 565-85I,

South Korea

Tel +82632382896

Fax +82632383832

Email sangmih@korea.kr

\begin{abstract}
Facial wrinkles are an undesirable outcome caused by extrinsic photodamage and intrinsic aging processes. Currently, no effective strategies are known to prevent facial wrinkles. We assessed the beneficial effects of bee-venom serum on the clinical signs of aging skin. Our results show that bee-venom serum treatment clinically improved facial wrinkles by decreasing total wrinkle area, total wrinkle count, and average wrinkle depth. Therefore, bee-venom serum may be effective for the improvement of skin wrinkles.
\end{abstract}

Keywords: bee venom, wrinkle, area, count, depth

\section{Introduction}

As the largest organ in the human body, the skin undergoes an aging process like all the other organs in the body. Both intrinsic and extrinsic factors contribute to skin aging via collagen alteration. While chronic sun exposure, especially to ultraviolet (UV) rays, is the dominant extrinsic aging cause, the passage of time is the main intrinsic aging factor. The characteristics of the aging process are the result of epidermal thinning, atypia of keratinocytes, and collagen degradation, which can be attributed to increased synthesis of collagenase. ${ }^{1}$ Reduction of collagen production subsequently causes the decrease of skin elasticity and collapse of fibroblasts to result in wrinkle formation.

Cosmeceuticals are skin-care products that cater for both cosmetics and drugs. ${ }^{2}$ The desire for the improvement of aging skin has resulted in a large volume of products to improve the appearance of skin. Many ingredients have been added to these cosmeceuticals, and honeybee venom is one of them. Since the beginning of the twentieth century, multiple therapeutic applications for bee venom have been developed for certain disorders. Given the anti-inflammatory and analgesic properties of bee venom, various forms of bee-venom therapy have been used for rheumatoid arthritis and multiple sclerosis. ${ }^{3}$ This traditional medicine has also been used for other diseases like cancer ${ }^{4}$ and even for Parkinson's disease. ${ }^{5}$ In addition, purified bee venom from Apis mellifera has been applied for skin conditions due to its antimicrobial properties. ${ }^{6}$

Honeybee-venom serum was developed as a cosmeceutical for reducing the wrinkle formation associated with the aging process. However, there has been little research into the antiwrinkle effects of bee venom-containing cosmetics in humans. Therefore, the aim of the present study was to investigate the antiwrinkle effects of topical application of bee-venom serum.

\section{Materials and methods Purified bee-venom collection and manufacture of bee-venom serum}

All experimental procedures used in the present study were approved by the Animal Care and Use Committee at the National Academy of Agricultural Science (NAAS), 
South Korea. Experimental colonies of natural honey bees (A. mellifera L.) used in this study were maintained at NAAS. Bee venom was collected with a bee-venom collector (Chungjin Biotech, Ansan, South Korea) in a sterile manner under strict laboratory conditions. In brief, the beevenom collector was placed on the hive, and the bees were given enough electric shocks to cause them to sting a glass plate, from which dried bee venom was later scraped off. The collected venom was diluted in cold sterile water and then centrifuged at $10,000 \mathrm{~g}$ for 5 minutes at $4^{\circ} \mathrm{C}$ to discard residues from the supernatant. Purified bee venom was lyophilized by freeze-drying and refrigerated at $4{ }^{\circ} \mathrm{C}$ for later use. Honeybee-venom serum was manufactured by using the approved materials of the International Cosmetic Ingredient Dictionary and formulated by following the instructions of the manufacturer, Dong Sung Pharmaceutical Co Ltd (Seoul, South Korea). For use in this study, bee-venom facial serum at a concentration of $0.006 \%$ bee venom was formulated.

\section{Subjects}

The clinical study was performed in accordance with the International Committee on Harmonisation Good Clinical Practice guidelines and the revised version of the Declaration of Helsinki. The trial protocol was approved by the institutional review board of Kyung Hee University Skin Biotechnology Center. Twenty-two generally healthy South Korean women aged between 30 and 49 years were selected from volunteers. All procedures involved in the study were explained in detail to volunteers, and written informed consent was obtained prior to entering the study. All subjects fulfilled inclusion criteria for periorbital wrinkles (global photodamage score 1-6), ${ }^{7}$ confirmed by a dermatologist's physical examination. Ten patients had mild photodamage (grades 2-3 on a 0-7 scale), and 12 had moderate photodamage (grades 4-5 on a 0-7 scale). For skin types, eight had dry skin, four normal skin, and ten a combination (dry, normal, and oily). Subjects with concomitant treatments, a propensity for pregnancy, use of anti-inflammatory drugs or immunosuppressants, chronic sickness, and wrinkle removal or peeling procedures within the last 6 months were excluded. Subjects were instructed to apply the treatment serum (Table 1) on their entire facial skin at an amount of $4 \mathrm{~mL}$ twice daily in the morning and evening for 12 weeks. Clinical evaluations were made at weeks 0 (baseline), 4, 8, and 12. A dermatologist's visual assessment, photographs, and image analysis of replicas were used to evaluate changes in skin wrinkles. Replicas of wrinkles in the left and right periorbital areas were acquired.
Table I Formulation of bee-venom serum

\begin{tabular}{lll}
\hline Ingredients & \multicolumn{2}{l}{ Composition $(w t \%)$} \\
\cline { 2 - 3 } & Control & $\begin{array}{l}\text { BV-containing } \\
\text { cosmeceutical }\end{array}$ \\
\hline Water & 90.365 & 90.359 \\
Butylene glycol & 6.00 & 6.00 \\
Alcohol & 3.00 & 3.00 \\
PEG-60 hydrogenated castor oil & 0.30 & 0.30 \\
Methylparaben & 0.10 & 0.10 \\
Sodium citrate & 0.08 & 0.08 \\
Fragrance & 0.055 & 0.055 \\
Disodium EDTA & 0.05 & 0.05 \\
Allantoin & 0.03 & 0.03 \\
Citric acid & 0.02 & 0.02 \\
Bee venom & - & 0.006 \\
\hline
\end{tabular}

Abbreviations: BV, bee venom; PEG, polyethylene glycol; EDTA, ethylenediaminetetraacetic acid.

\section{Visual assessment of subjects}

For a couple of hours preceding the clinic visit at weeks 0, 4, 8 , and 12 , subjects were instructed not to make any changes to their daily skin-care routine or expose their face to intense sunlight. Upon arrival, subjects washed their face with a mild or soapless nonmedicated cleanser and waited 20 minutes at a constant temperature $\left(22^{\circ} \mathrm{C} \pm 2^{\circ} \mathrm{C}\right)$ and humidity $(50 \% \pm 5 \%)$ before assessment by a dermatologist. Subjects' periorbital wrinkles were evaluated with a double-blind test by two dermatologists based on a wrinkle grade (Table 2), which was developed by the Korea Food and Drug Administration. ${ }^{8}$ Subjects' periorbital wrinkles were classified into ten grades. Medical photographs of periorbital wrinkles were taken at each visit by a Facial Stage DM-3 (Schott Moritex Corporation, Asaka, Japan).

\section{Image analysis using replicas}

Wrinkle improvement was evaluated by measuring total wrinkle area, total wrinkle count, and total wrinkle depth

Table 2 South Korean wrinkle-grading system*

\begin{tabular}{ll}
\hline Grade & Description \\
\hline 0 & No wrinkles, and skin is fine \\
\hline & Some signs of fine wrinkles \\
3 & Some fine wrinkles \\
& A lot of fine wrinkles, and some are progressing \\
4 & into slightly deeper wrinkles \\
5 & Some slightly deeper wrinkles \\
6 & Slightly deeper wrinkles have become more defined; \\
7 & however, there are no signs of deep wrinkles \\
8 & Signs of slightly deeper wrinkles turning into deep \\
9 & wrinkles \\
\hline
\end{tabular}

Note: *Korea Food and Drug Administration, 2005. 
using the Visioline VL6 50 (Courage + Khazaka GmbH, Cologne, Germany). Skin-surface replicas of crow's feet from right and left periorbital areas were obtained at weeks 0 , 4,8 , and 12 .

\section{Self-assessment questionnaire}

Subject self-assessments via questionnaire were made at weeks 4, 8, and 12. Subjects rated their facial skin condition and the product's efficacy on a 4-point scale (strongly agree, agree, disagree, and strongly disagree).

\section{Statistical analysis}

Data are presented as mean \pm standard deviation. Changes from baseline in wrinkle parameters were evaluated. The paired $t$-test was used to determine the statistical significance of differences in efficacy of bee-venom serum. Data analysis was performed using SPSS software version 20.0 (IBM Corporation, Armonk, NY, USA).

\section{Results}

As shown in Table 3, the average visual grade of all patients significantly improved with the bee-venom serum treatment at weeks 8 (6.64\% decrement, $P=0.002)$ and $12(11.83 \%$ decrement, $P=0.0003)$ when compared with the baseline decrement $(2.49 \%)$. Total wrinkle area decreased in a timedependent manner after treatment with bee-venom serum from $26.04 \pm 3.46 \mathrm{~mm}^{2}$ at baseline to $25.75 \pm 3.31 \mathrm{~mm}^{2}$, $24.84 \pm 3.61 \mathrm{~mm}^{2}$, and $24.44 \pm 2.69 \mathrm{~mm}^{2}$ at weeks 4,8 , and 12 , respectively (Figure 1). Total wrinkle count (Figure 2) was affected by different periods of treatment (week 0 , 104.05 \pm 31.96 ; week 4, 103.05 \pm 32.39 ; week 8, 105.00 \pm 42.11 ; week 12, 99.91 \pm 32.17$)$. Likewise, time-dependent decrease in average wrinkle depth (Figure 3) from bee-venom serum application was observed (week 0, 361.46 $\pm 94.48 \mu \mathrm{m}$;

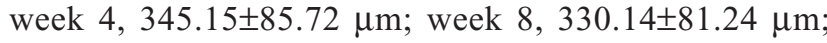
week 12, $321.08 \pm 78.91 \mu \mathrm{m})$. Analysis on these three parameters revealed that a statistically significant difference was observed only at week 12 . Facial images and replicas from

Table 3 Changes in visual wrinkle-grading scores in patients treated with bee-venom serum

\begin{tabular}{llll}
\hline Week & Grade & Decrement (\%) & P-value $^{\mathrm{b}}$ \\
\hline 0 & $4.82 \pm 0.98$ & - & \\
4 & $4.70 \pm 1.03$ & 2.49 & 0.057 \\
8 & $4.50 \pm 1.07$ & 6.64 & $0.002^{*}$ \\
12 & $4.25 \pm 1.02$ & 11.83 & $0.0003^{* *}$ \\
\hline
\end{tabular}

Notes: a Decrement: $(\mathrm{W} x-\mathrm{W} 0) / \mathrm{W} 0 \times 100$; ${ }^{b}$ paired $t$-test; $* P<0.01$; $* * P<0.001$. Abbreviation: $\mathrm{W}$, week.

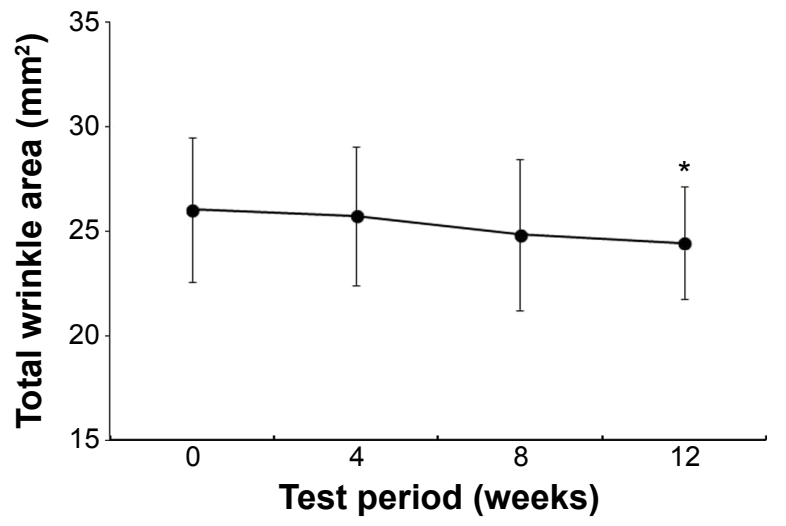

Figure I Changes in total wrinkle area analyzed by the Visioline VL 650 after 12 weeks of treatment with bee-venom serum.

Note: $* P<0.05$

crow's feet of periorbital areas were taken. Figure 4 illustrates the notable improvement in wrinkles after 12 weeks of bee-venom serum treatment. Subject responses to all questions in the self-assessment questionnaire at weeks 4 , 8 , and 12 showed favorable improvements (Figure 5). These data indicate a great effect of bee-venom serum on wrinkle improvement.

\section{Discussion}

The main aim of the present study was to evaluate the clinical effects of bee-venom serum by measuring clinical wrinkles objectively with a device that converts wrinkle roughness to numerical values. This is the first clinical study to determine the effects of bee venom-containing cosmetics on facial wrinkles in human skin. In this research, we found that bee-venom serum treatment clinically improved facial wrinkles by decreasing total wrinkle area, total wrinkle count, and average wrinkle depth.

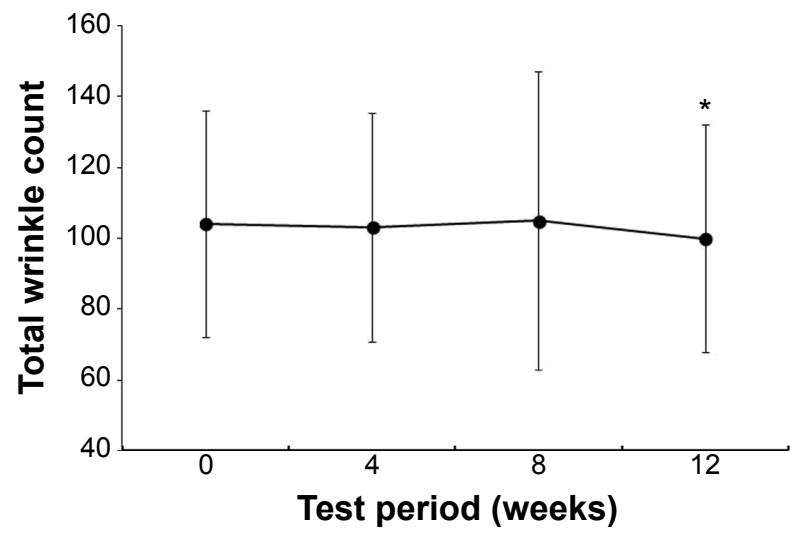

Figure 2 Changes in total wrinkle count analyzed by the Visioline VL 650 after 12 weeks of treatment with bee-venom serum. Note: $* p<0.05$ 


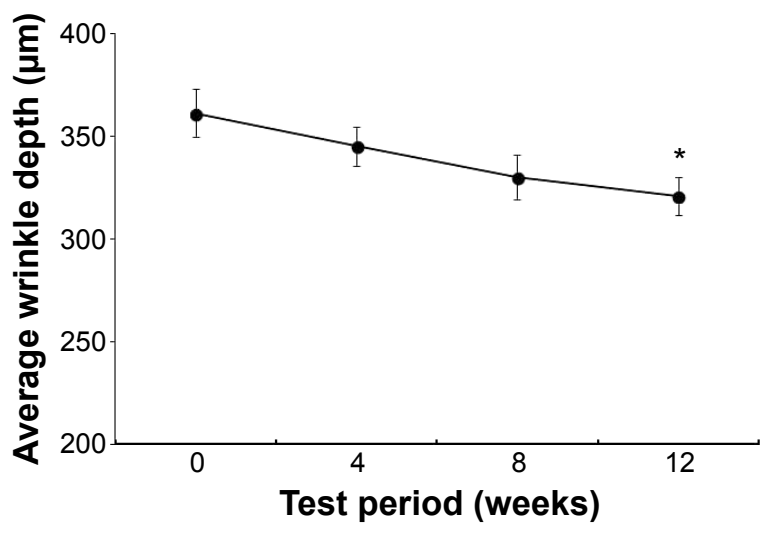

Figure 3 Changes in average wrinkle depth analyzed by the Visioline VL 650 after 12 weeks of treatment with bee-venom serum. Note: $* p<0.05$.
The mechanism by which bee-venom serum exerts its antiwrinkle effects is unknown. The therapeutic action of bee venom has been studied mostly for skin-related symptoms, at least by our group of researchers. When skin bacteria were incubated with bee venom, a bacteriostatic action of bee venom was demonstrated, which was further supported by its anti-inflammatory activity against skin bacteria through suppression of the secretion of proinflammatory cytokines. ${ }^{9}$ This in vitro action of an antimicrobial property in bee-venom study was further translated into an in vivo study of human subjects with acne vulgaris. ${ }^{6}$ Repeated exposure to UV irradiation induces an elevated secretion of matrix-degrading enzymes called matrix

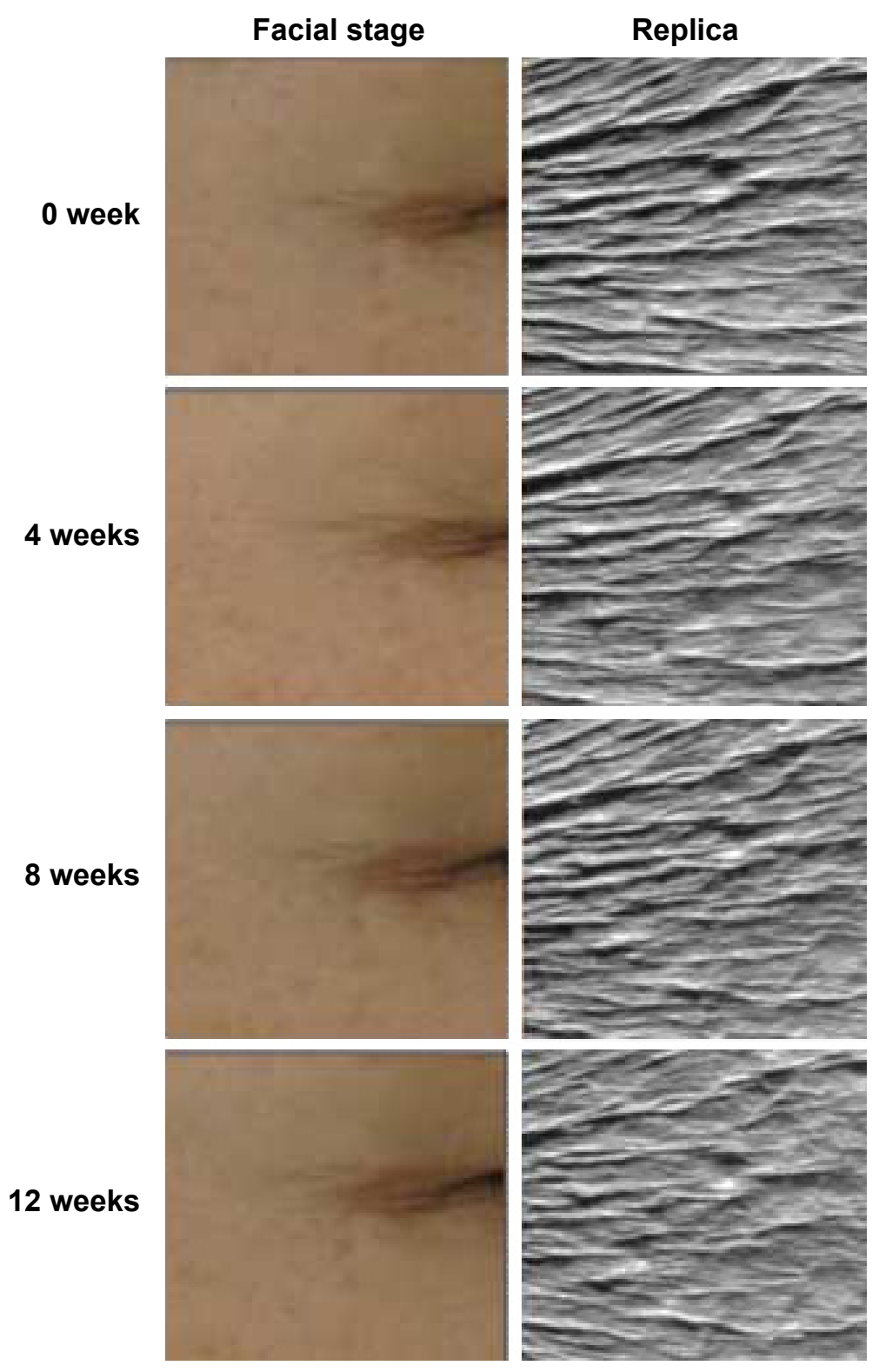

Figure 4 Representative facial images and replicas of wrinkle improvement in the crow's feet area at baseline and after 4,8 , and I 2 weeks of bee-venom serum use. 


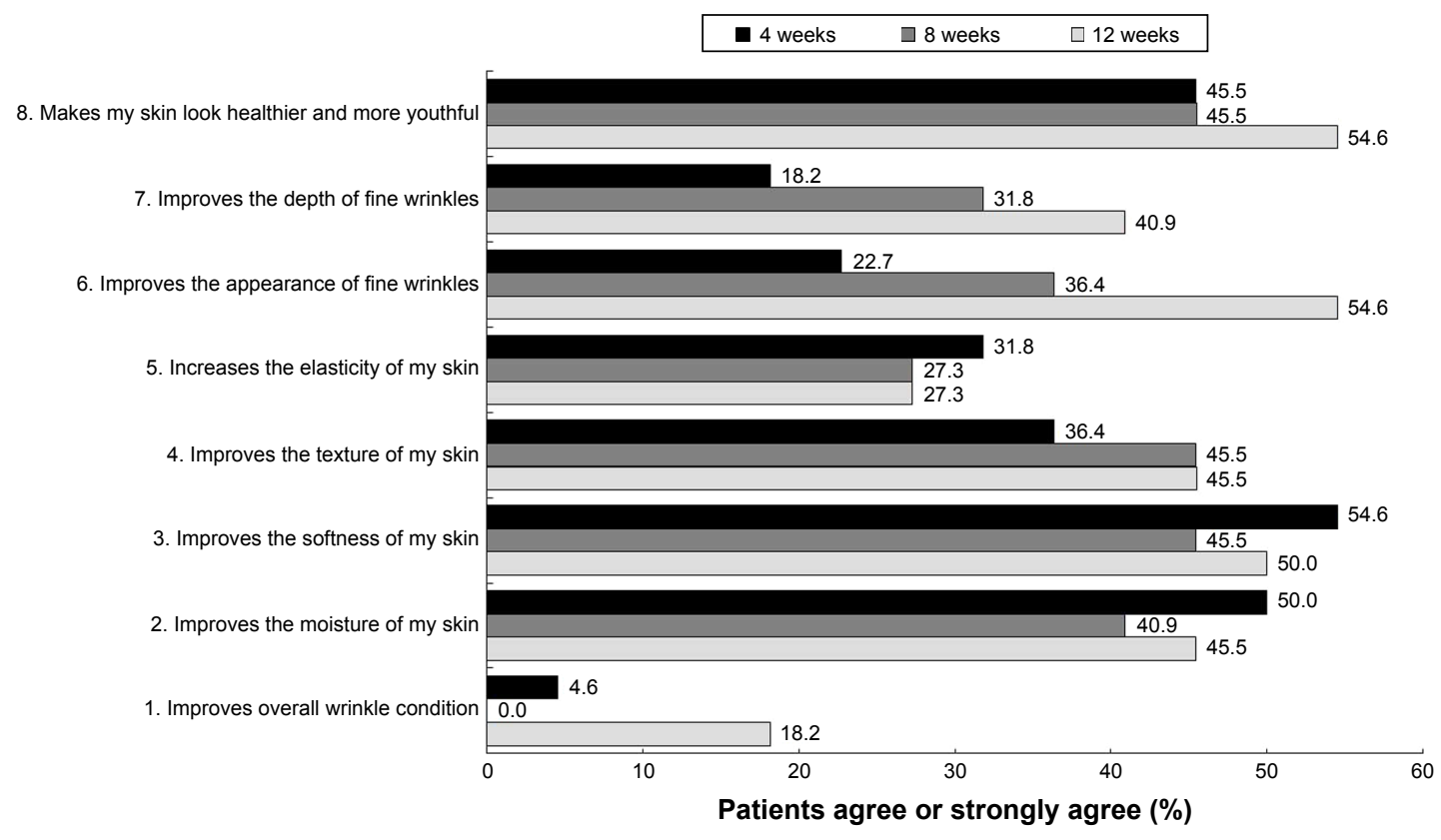

Figure 5 Subject self-assessment of bee-venom serum attributes after 4, 8, and 12 weeks' treatment.

metalloproteinases (MMPs). With human dermal fibroblasts, bee venom markedly reduced UV-induced MMP protein levels compared with those of UV-irradiated controls. ${ }^{10}$ This was attributed to the presence of an antimelanogenic property of bee venom by inhibiting tyrosinase-related proteins. ${ }^{11}$ Similarly, dietary Aloe vera supplementation improved facial wrinkles by causing a significant decrease in MMP-1 messenger RNA levels. ${ }^{12}$ When wounded mice were treated topically with bee venom, increased collagen protein synthesis was demonstrated, ${ }^{13}$ which might be related to increased proliferation and migration of human epidermal keratinocytes. ${ }^{14}$ Bee venom as a cosmetic ingredient may be useful as a topical agent for promoting skin regeneration or a treatment of certain epidermal conditions. Topical application of bee venom can be well tolerated in the human skin, because it has exhibited no dermal irritation potential in animal studies. ${ }^{15}$

The main aim of this study was to evaluate the clinical effects of bee-venom serum. We analyzed images using replicas and the Visioline device, which is an objective technique to reproduce changes in photodamaged skin. The image analysis using replicas was performed at week 12, when significant differences in total wrinkle area, total wrinkle count, and average wrinkle depth were observed. This analysis correlated well with the clinical findings. Moreover, a significant difference in visual grade was observed after 8 weeks with bee-venom serum, indicating the faster effect of bee-venom serum on wrinkle improvement.
Our findings suggest that bee venom plays an important role in the improvement of skin wrinkles, and it is used in the cosmetics industry as an antiwrinkle agent. Bee-venom serum provided greater efficacy in terms of total wrinkle area, total wrinkle count, and average wrinkle depth in subjects with photodamaged skin. Long-term treatment with bee venomcontaining cosmetics could be safe, because the irritation potential of bee venom is negligible.

\section{Acknowledgment}

This work was supported by a grant from the support of Cooperative Research Program for Agriculture Science and Technology Development (project PJ01132503), Rural Development Administration, Republic of Korea.

\section{Disclosure}

The authors report no conflicts of interest in this work.

\section{References}

1. Cho JM, Lee YH, Baek RM, Lee SW. Effect of platelet-rich plasma on ultraviolet B-induced skin wrinkles in nude mice. J Plast Reconstr Aesthet Surg. 2011;64(2):e31-e39.

2. Lupo MP. Cosmeceutical peptides. Dermatol Surg. 2005;31(7 Pt 2): 832-836.

3. Munstedt J, Hackethal A, Schmidt K. Bee venom therapy, bee venom acupuncture of apiculture: what is the evidence behind the various health claims? Am Bee J. 2005; 145:665-668.

4. Oršolić N. Bee venom in cancer therapy. Cancer Metastasis Rev. 2012; 31(1-2):173-194.

5. Cho SY, Shim SR, Rhee HY, et al. Effectiveness of acupuncture and bee venom acupuncture in idiopathic Parkinson's disease. Parkinsonism Relat Disord. 2012;18(8):948-952. 
6. Han SM, Lee KG, Pak SC. Effects of cosmetics containing purified honeybee (Apis mellifera L.) venom on acne vulgaris. J Integr Med. 2013;11(5):320-326.

7. Chung JH, Lee SH, Youn CS, et al. Cutaneous photodamage in Koreans: influence of sex, sun exposure, smoking, and skin color. Arch Dermatol. 2001;137(8):1043-1051.

8. Korea Food and Drug Administration. Guideline for Efficacy Evaluation of Functional Cosmetics. Cheongju, South Korea: KFDA; 2005.

9. Han SM, Lee KG, Yeo JH, Baek HJ, Park KK. Antibacterial and anti-inflammatory effects of honeybee (Apis mellifera) venom against acne-inducing bacteria. J Med Plant Res. 2010;4(6):459-464.

10. Han SM, Lee KG, Yeo JH, et al. Inhibitory effect of bee venom against ultraviolet B induced MMP-1 and MMP-3 in human dermal fibroblasts. J Apic Res. 2007;46(2):94-98.

11. Han SM, Kim JM, Pak SC. Anti-melanogenic properties of honeybee (Apis mellifera $\mathrm{L}$.) venom in $\alpha-\mathrm{MSH}$-stimulated B16F1 cells. Food Agric Immunol. 2015;26(3):451-462.
12. Cho S, Lee S, Lee MJ, et al. Dietary Aloe vera supplementation improves facial wrinkles and elasticity and it increases the type I procollagen gene expression in human skin in vivo. Ann Dermatol. 2009;21(1):6-11.

13. Han SM, Lee KG, Yeo JH, Kim WT, Park KK. Biological effects of treatment of an animal skin wound with honeybee (Apis mellifera L.) venom. J Plast Reconstr Aesthet Surg. 2011;64(3):e67-e72.

14. Han SM, Park KK, Nicholls YM, Macfarlane N, Duncan G. Effects of honeybee (Apis mellifera) venom on keratinocyte. Pharmacogn Mag. 2013;9(35):220-226.

15. Han SM, Lee KG, Park KK, Pak SC. Skin sensitization study of bee venom (Apis mellifera L.) in guinea pigs and rats. Cutan Ocul Toxicol. 2013;32(1):27-30.
Clinical Interventions in Aging

\section{Publish your work in this journal}

Clinical Interventions in Aging is an international, peer-reviewed journal focusing on evidence-based reports on the value or lack thereof of treatments intended to prevent or delay the onset of maladaptive correlates of aging in human beings. This journal is indexed on PubMed Central, MedLine,

\section{Dovepress}

CAS, Scopus and the Elsevier Bibliographic databases. The manuscript management system is completely online and includes a very quick and fair peer-review system, which is all easy to use. Visit http://www.dovepress. com/testimonials.php to read real quotes from published authors. 